\title{
First Report of Sclerotinia minor Infecting Eclipta prostrata in Texas
}

\begin{abstract}
J. E. Woodward ${ }^{\dagger}$ and P. A. Dotray, Texas A\&M AgriLife Research \& Extension Center, Lubbock, TX 79403, and Texas Tech University, Department of Plant and Soil Science, Lubbock, TX 79409; J. M. Cason, Texas A\&M AgriLife Research \& Extension Center, Stephenville, TX 76401; and T. A. Baughman, Institute for Agricultural Biosciences, Oklahoma State University, Ardmore, OK 73401
\end{abstract}

Accepted for publication 25 September 2017.

Sclerotinia blight, caused by the soilborne fungus Sclerotinia minor Jagger, is an economically important disease of peanut (Arachis hypogaea L.) in North Carolina, Oklahoma, Texas, and Virginia. The fungus has a broad host range capable of infecting plants from 21 different plant families (Melzer et al. 1997) including numerous weeds commonly found in peanut fields (Hollowell et al. 2003).

Symptoms characteristic of Sclerotinia blight were observed on Eclipta prostrata L., which belongs to the family Asteraceae (Fig. 1). Samples were collected from the perimeter of three peanut fields known to be infested with $S$. minor near Stephenville, TX, in September of 2009. Infected plants were wilted and exhibited yellow leaves (Fig. 2). Stems of infected plants were covered with white mycelia and had a bleached appearance (Fig. 3). Small black sclerotia (diameter $<2.0 \mathrm{~mm}$ ) later formed abundantly on diseased stems. Similar symptoms were observed on peanut cultivar Tamnut OL02 in the field (Fig. 4). Symptomatic E. prostrata stem sections $(n=10)$ were rinsed in tap water, surface disinfested in $0.5 \%$ sodium hypochlorite for $1 \mathrm{~min}$, air dried, and placed in Petri dishes containing potato dextrose agar (PDA). Pure cultures of $S$. minor consisting of white, aerial mycelia and small, black, irregular sclerotia (Fig. 5) were recovered from all samples. Pathogenicity tests were conducted by inoculating detached shoots of $E$. prostrata that were transplanted in one-gallon plastic pots containing sterile potting mix and peanut seedlings cv. Flavorrunner $458(n=5)$ with PDA plugs obtained

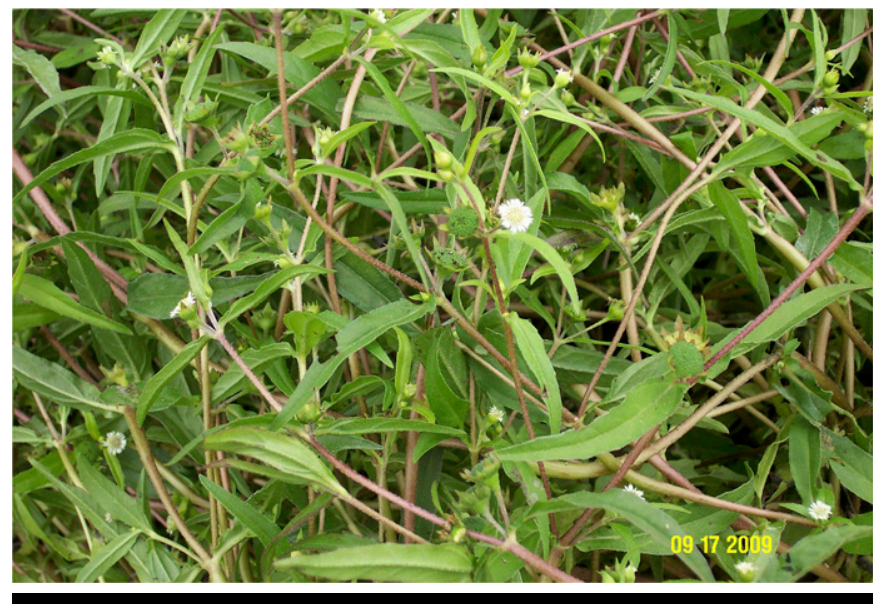

FIGURE 1

Overview of mature Eclipta prostrata plants showing leaves and flowers.

Corresponding author: J. E. Woodward; E-mail: jewoodward@ag.tamu.edu

(C) 2017 The American Phytopathological Society from the edges of four-day-old $S$. minor cultures. Plants were incubated in a dew chamber at $20^{\circ} \mathrm{C}$ and $95 \%$ relative humidity for three days. Plants inoculated with sterile PDA plugs $(n=3)$ served as controls. Symptoms typical of Sclerotinia blight (Porter and Melouk 1997) were observed on all inoculated plants, but not on the noninoculated controls. Cultures of $S$. minor were recovered from both

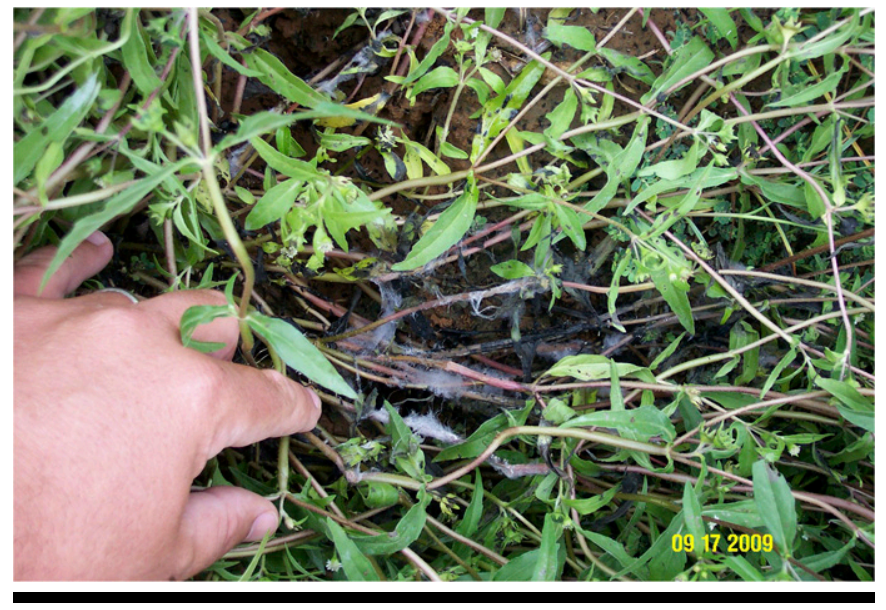

FIGURE 2

Appearance of Eclipta prostrata plants exhibiting symptoms of Sclerotinia blight and signs of the causal agent Sclerotinia minor.

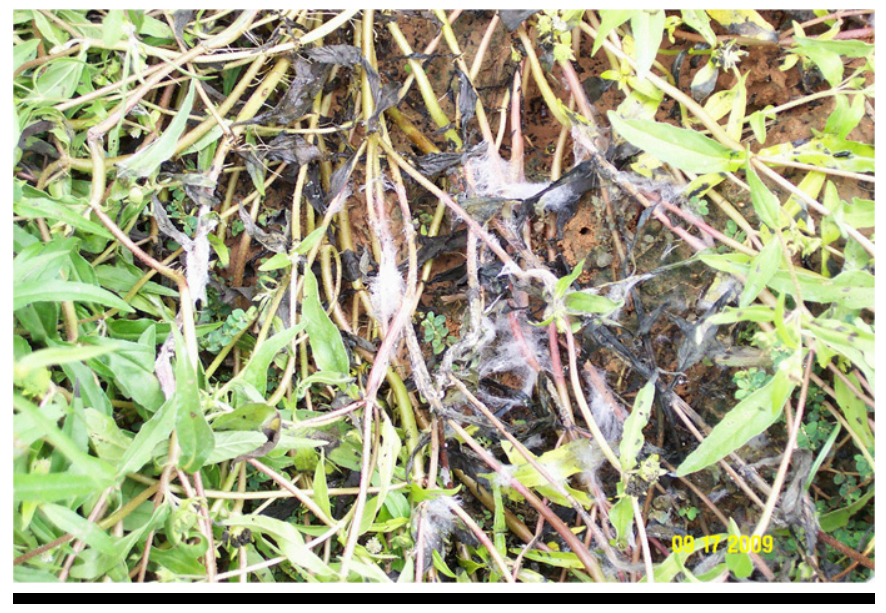

FIGURE 3

Matting of leaves and bleaching of stems from Eclipta prostrata infected by Sclerotinia minor. 


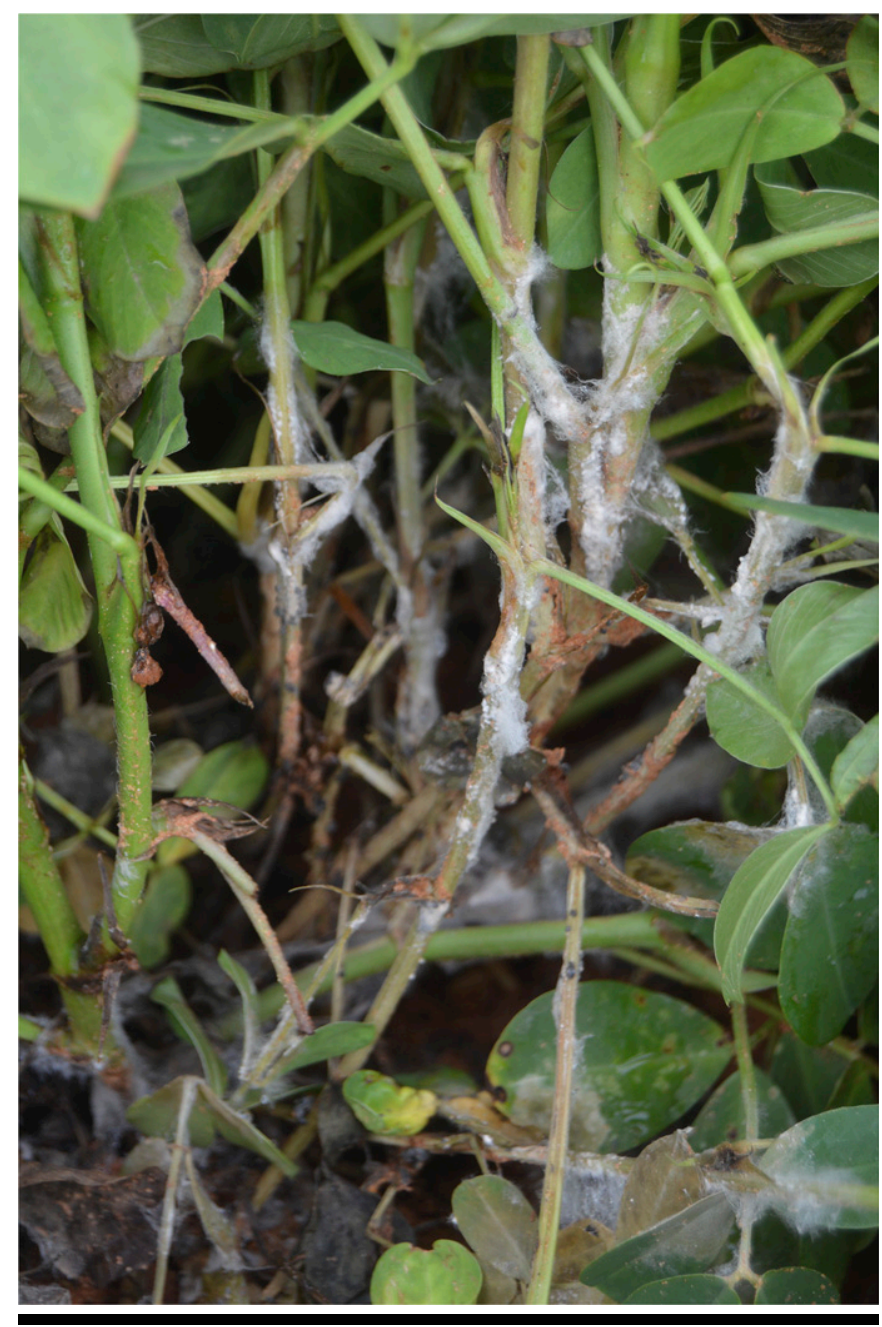

FIGURE 4

Characteristic symptoms and signs of Sclerotinia blight of peanut, caused by Sclerotinia minor, in a field near Stephenville, TX.

symptomatic peanut and E. prostrata tissues. Inoculations were repeated and similar results were observed.

Eclipta prostrata has been reported as a host of S. minor in Oklahoma (Melouk et al. 1989) and several other weed species including Ipomoea hederacea and I. coccinea, which have also been identified as alternative hosts for $S$. minor in Texas (Woodward et al. 2008). To our knowledge, this is the first report of S. minor infecting E. prostrata in Texas. Weed management decisions should be included in the overall development and implementation of disease management strategies for S. minor. Failure to properly

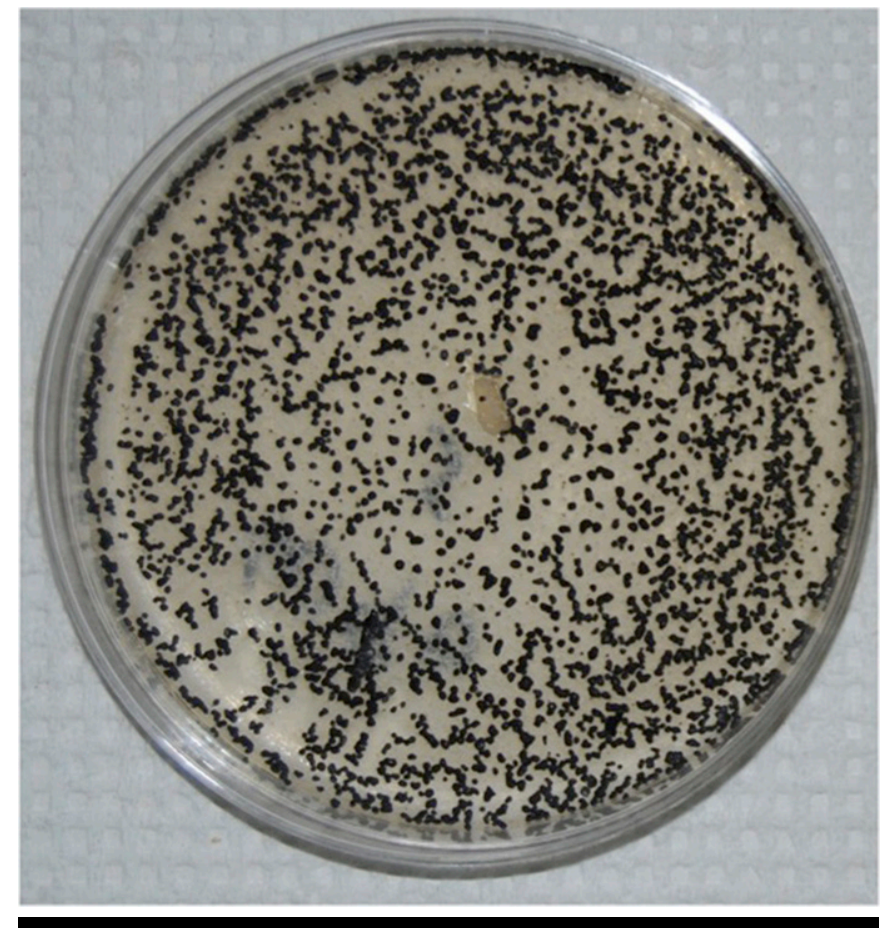

FIGURE 5

Culture characteristics of a Sclerotinia minor isolate obtained from Eclipta prostrata growing on the edge of a peanut-production field near Stephenville, TX.

manage weeds in rotational crops or fallow periods will potentially lead to an increase in densities of sclerotia in the soil that will serve as inoculum for Sclerotinia blight development in subsequent peanut crops. The lack of control of weeds that serve as a host for S. minor would reduce the effectiveness of crop rotation as a part of a disease management plan.

\section{Literature Cited}

Hollowell, J. E., Shew, B. B., Cubeta, M. A., and Wilcut, J. W. 2003. Weed species as hosts of Sclerotinia minor in peanut fields. Plant Dis. 87:197-199.

Melouk, H. A., Damicone, J. P., and Jackson, K. E. 1989. Eclipta prostrata, a new weed host for Sclerotinia minor. Plant Dis. 73:68.

Melzer, M. S., Smith, E. A., and Boland, G. J. 1997. Index of plant hosts of Sclerotinia minor. Can. J. Plant Pathol. 19:272-280.

Porter, D. M., and Melouk, H. A. 1997. Sclerotinia blight. Page 34 in: Compendium of Peanut Diseases, 2nd ed. N. Kokalis-Burelle, D. M. Porter, R. Rodríguez-Kábana, D. H. Smith, and P. Subrahmanyam, eds. The American Phytopathological Society, St. Paul, MN.

Woodward, J. E., Batla, M. A., Dotray, P. A., Wheeler, T. A., and Baughman, T. A. 2008. First report of Sclerotinia minor infecting Ipomoea hederacea and I. coccinea in Texas. Plant Dis. 92:482. 